\title{
CRDS Study of Tropospheric Ozone Production Kinetics : Isoprene Oxidation by Hydroxyl Radical
}

\author{
Ji-Ho Park \\ Department of Environmental Health, Korean National Open University, Seoul 110-791, Korea
}

(Received November 4, 2009/Revised November 20, 2009/Accepted December 5, 2009)

\begin{abstract}
The tropospheric ozone production mechanism for the gas phase additive oxidation reaction of hydroxyl radical $(\mathrm{OH})$ with isoprene (2-methyl-1,3-butadiene) has been studied using cavity ring-down spectroscopy (CRDS) at total pressure of 50 Torr and $298 \mathrm{~K}$. The applicability of CRDS was confirmed by monitoring the shorter ( 4\%) ringdown time in the presence of hydroxyl radical than the ring-down time without the photolysis of hydrogen peroxide. The reaction rate constant, $(9.8 \pm 0.1) \times 10^{-11} \mathrm{molecule}^{-1} \mathrm{~cm}^{3} \mathrm{~s}^{-1}$, for the addition of $\mathrm{OH}$ to isoprene is in good agreement with previous studies. In the presence of $\mathrm{O}_{2}$ and $\mathrm{NO}$, hydroxyl radical cycling has been monitored and the simulation using the recommended elementary reaction rate constants as the basis to $\mathrm{OH}$ cycling curve gives reasonable fit to the data.
\end{abstract}

Keywords: cavity ring-down spectroscopy, ozone, isoprene, oxidation, rate constant

\section{Introduction}

Among the issues in regional air quality, the tropospheric ozone production through the photochemical oxidation of unsaturated hydrocarbons has been drawing attention of many atmospheric scientists. Isoprene (2-methyl-1,3-butadiene, $\mathrm{C}_{5} \mathrm{H}_{8}$ ) is the most abundant non-methane biogenic organic compound emitted by vegetation into the atmosphere $(\sim 450 \mathrm{Tg} / \mathrm{yr})$ and its oxidation serves as a major source of tropospheric ozone. ${ }^{1,2)}$ During the day time, isoprene reacts predominantly with the hydroxyl radical $(\mathrm{OH})$ which has tropospheric lifetime of a few seconds or less and the concentration of $\mathrm{OH}$ in the sunlit troposphere is near $10^{6}$ molecules $\left.\cdot \mathrm{cm}^{-3} .3\right)$

In the metropolitan city, the atmosphere is polluted by automobile exhaust gases including nitrogen oxides $\left(\mathrm{NO}_{\mathrm{x}}\right)^{4)}$ and isoprene is oxidized by $\mathrm{OH}$ in the presence of moderate concentration of $\mathrm{NO}$ as well as $\mathrm{O}_{2}$. The $\mathrm{OH}$ regeneration during

Corresponding author: Department of Environmental Health, Korean National Open University Tel: 82-2-3668-4742, Fax: 82-2-741-4701 E-mail: jihopark@knou.ac.kr isoprene oxidation in the presence of $\mathrm{NO}$ and $\mathrm{O}_{2}$ is abbreviately shown in Fig. 1. The first intermediate radical product, hydroxy alkyl radical $\left(\mathrm{HOC}_{5} \mathrm{H}_{8}\right)$, reacts with $\mathrm{O}_{2}$ to produce the hydroxy peroxy radical $\left(\mathrm{HOC}_{5} \mathrm{H}_{8} \mathrm{O}_{2}\right)$. The reaction between hydroxy peroxy radicals and NO yields alkoxy radical $\left(\mathrm{HOC}_{5} \mathrm{H}_{8} \mathrm{O}\right)$ and nitrogen dioxide. The decomposition of alkoxy radicals, followed by the $\mathrm{HO}_{2}+\mathrm{NO}$ reaction regenerates $\mathrm{OH}$ radical. It is worth noting that each cycle of the isoprene oxidation produces two molecules of ozone from the reaction between $\mathrm{O}_{2}$ and $\mathrm{O}$ followed by photolysis of nitrogen dioxide.

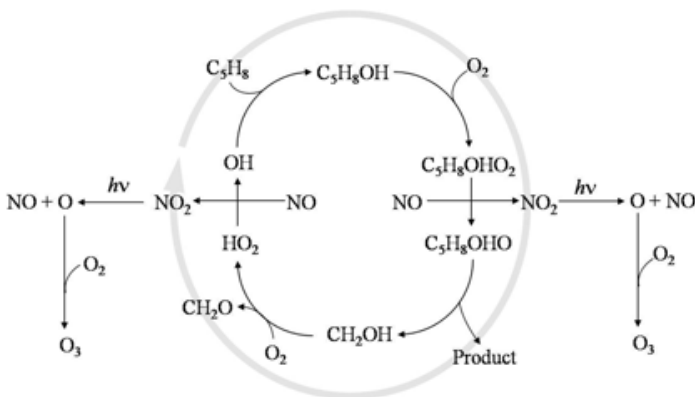

Fig. 1. Schematic diagram showing the $\mathrm{OH}$ initiated isoprene oxidation cycle which results in ozone production. 
Furthermore, the following oxidation processes of isoprene oxidation products such as methyl vinyl ketone, methacrolein, acrolein, and 3-methylfurane produce more ozone in the troposphere. It is also crucial to determine the yield distribution of those first oxidation products since the impacts on the elevation of the tropospheric ozone concentration by each of them are different. In this regard, careful tracing of isoprene oxidation process through theoretical or experimental kinetic studies is important for understanding detail isoprene oxidation mechanism which reveals the end product distribution. From the kinetic study, the rates of elementary reactions are determined and the information on the dominant reaction path can be provided by comparing the reaction rates when there are several possible reactions competing.

Initial reaction of isoprene and $\mathrm{OH}$ can result in four possible adducts and the initial branching ratios among these hydroxy alkyl radicals strongly influence the final product distribution. There have been several theoretical and end product analysis studies ${ }^{5-10)}$ suggesting a preference for $\mathrm{OH}$ addition to the terminal carbons although a recent mass spectrometry study ${ }^{11)}$ indicates comparable yields of all four radicals. Despite the discrepancy in the initial branching ratios, there is general consensus regarding the rate constant of $(1.0 \pm$ $0.1) \times 10^{-10}$ molecule $^{-1} \mathrm{~cm}^{3} \mathrm{~s}^{-1}$ at $298 \mathrm{~K}^{11-15)}$

In the presence of $\mathrm{O}_{2}$, the hydroxy alkyl radicals react with $\mathrm{O}_{2}$ forming peroxy radicals $\left(\mathrm{RO}_{2}\right)$. The reported overall reaction rate constants ${ }^{16,17)}$ are in the range from $1 \times 10^{-13}$ to $8 \times 10^{-11}$ molecule $e^{-1} \mathrm{~cm}^{3} \mathrm{~s}^{-1}$ and there is little of direct measurement studies on the formation rate of $\mathrm{RO}_{2}$ due to the difficulty in monitoring $\mathrm{RO}_{2}$. A direct measurement study by Zhang et al ${ }^{18)}$ using fast flow reactor coupled to chemical ionization mass spectrometry detection determined the rate constant of $(7 \pm 3) \times 10^{-13}$ molecule $^{-1}$ $\mathrm{cm}^{3} \mathrm{~s}^{-1}$ and it is more than an order of magnitude larger than the previous report of $(2.8 \pm 0.7) \times 10^{-15}$ molecule ${ }^{-1} \mathrm{~cm}^{3} \mathrm{~s}^{-1}$ which was obtained by detecting the loss of hydroxy alkyl radicals by the same group. ${ }^{19)}$ Although the authors claim the interference by the $\mathrm{RO}_{2}$ decomposition resulted in the previous low value, the differences still remain between their recent value and the other suggested rate constants range from $2 \times 10^{-12}$ to $8 \times 10^{-11}$ molecule $^{-1}$ $\mathrm{cm}^{3} \mathrm{~s}^{-1}$ obtained by indirect $\mathrm{OH}$ cycling experiments. In this regard, UV absorption spectroscopy shall be considered as a efficient method to determine $\mathrm{RO}_{2}$ formation rate using $\mathrm{OH}$ cycling experiments. There have been difficulties in monitoring the fluorescence of $\mathrm{OH}$ due to the high fluorescence quenching efficiency of $\mathrm{O}_{2}$ when laser photolysis/ laser-induced fluorescence (LP/LIF) spectroscopy is used with high concentration of $\mathrm{O}_{2}$. High concentration of $\mathrm{O}_{2}$ provides more dramatic $\mathrm{OH}$ signal rise (cycling) at earlier time of the isoprene $+\mathrm{OH}+\mathrm{O}_{2}$ reaction and this gives more detail information of $\mathrm{O}_{2}$ addition to hydroxy alkyl radical. On the contrary, the absorption method is free from the quenching problem and the temporal profile of $\mathrm{OH}$ can be efficiently detected. Recently, various studies ${ }^{20-23)}$ using cavity ring-down spectroscopic (CRDS) detection method which basically uses absorption property of the object species have been adopted due to its simplicity: absorption is derived from the increased decay rate of laser radiation within a stable optical cavity induced by absorbing species. Especially, CRDS is an excellent detection method for measuring kinetics of radical species and the sensitivity of CRDS is very high. Lin et $a .^{24,25)}$ have used CRDS for kinetics measurement for phenyl radical and Atkinson and Hudgens ${ }^{26-28)}$ have adopted CRDS for ethyl radicals, propargyl radicals and chloroally radicals.

In this study, a CRDS apparatus has been tested for measuring the rate constant of $\mathrm{OH}+$ isoprene addition reaction and it has been found the rate constant is in good agreement with previously reported values. $\mathrm{OH}$ cycling experiment also has been performed in the presence of $\mathrm{O}_{2}$ and $\mathrm{NO}$ at the total pressure of 50 Torr and $295 \mathrm{~K}$ and early $\mathrm{OH}$ cycling has been monitored with $\mathrm{O}_{2}$ partial pressure of 6 Torr.

\section{Experimental Section}

The experimental determination of the rate constants was performed using a slow flow cavity with a length of $60 \mathrm{~cm}$ and two highly reflective mirrors (reflectivity $>99.5 \%$ ) which have a $0.56 \mathrm{~m}$ radius of curvature were installed at the both ends of the reaction cavity. The cavity was evacuated by a mechanical pump and argon was used as a 
buffer gas. Throughout the experiment, the total pressure and temperature were maintained at 50 Torr and $295 \mathrm{~K}$, respectively. 90 95\% hydrogen peroxide $\left(\mathrm{H}_{2} \mathrm{O}_{2}\right)$ was prepared by vacuum distillation by checking the density of the solution and $\mathrm{H}_{2} \mathrm{O}_{2}$ was transferred into the cavity by flowing argon through a bubbler containing concentrated $\mathrm{H}_{2} \mathrm{O}_{2}$. Isoprene buffered with argon gas was prepared in a 5L bulb via freeze-pump-thaw method and introduced into the cavity using a mass flow controller to yield typical concentrations of $1 \times 10^{14}$ molecules $\mathrm{cm}^{-3}$. The NO was buffered with argon in a $5 \mathrm{~L}$ bulb to known concentrations and was introduced into the cavity through a flow controller. The concentrations of NO were varied from 0 to $1.6 \times 10^{15}$ molecules $\mathrm{cm}^{-3}$ and $\mathrm{O}_{2}$ concentration was fixed at 6 Torr $\left(1.96 \times 10^{17}\right.$ molecules $\left.\mathrm{cm}^{-3}\right)$.

Fig. 2 is a schematic diagram of cavity ringdown apparatus. The frequency doubled probe beam was generated by the Nd:YAG pumped dye laser with a pulse duration of $6 \sim 8 \mathrm{~ns}$ and $\mathrm{OH}$ from $\mathrm{H}_{2} \mathrm{O}_{2}$ photolysis was produced by the $248 \mathrm{~nm}$ beam from the excimer laser. The delay between the pump (excimer laser) and probe (dye laser) beam was adjusted by a delay generator. The probe beam leaking out of the exit mirror has been pointed to a photomultiplier tube which transferred analog signal proportional to the photon density to a digital oscilloscope. A computer was interfaced to the oscilloscope to analyze the ring down time. The temporal photon decay can be described by the equation

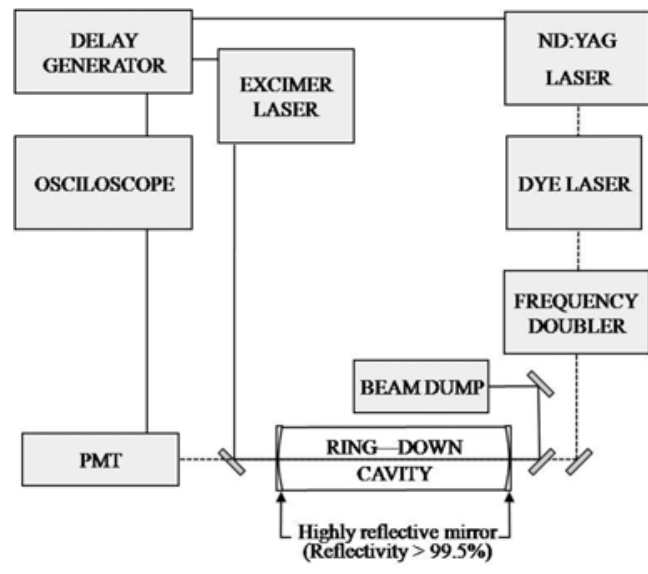

Fig. 2. Schematic diagram of the experiment.

$$
I(t)=I_{0} \cdot e^{-\left(\frac{1-R+L^{\prime} \alpha}{L}\right) c t}
$$

where $I$ is the number of photons detected by the photomultiplier tube, $I_{0}$ is the number of photons injected into the cavity, $L^{\prime}$ is the length of the absorbing medium which is the same as the length of cavity $(L)$ in this study, $c$ is the speed of light, and $R$ and $\alpha$ are mirror reflectivity and the absorption coefficient, respectively. When the averaged waveform is transformed to a log[intensity] vs. time profile, it was fit to a line using a least squares algorithm. The resulting slope of the line is the inverse of the time constant for the single exponential decay of light intensity from the cavity and it can be written as

$$
\frac{1}{t}=\frac{L^{\prime} \alpha c+(1-R) c}{L}
$$

where intrinsic ring-down time (without absorbing species) is given as

$$
\frac{1}{t_{0}}=\frac{(1-R) c}{L}
$$

Fig. 3 shows the temporal the ring-down profiles obtained in the absence (probe beam only) and the presence (pump and probe beam) of $\mathrm{OH}$ and the intrinsic ring-down time $\left(t_{0}\right)$ of $546 \mathrm{~ns}$ which corresponds mirror reflectivity of $99.6 \%$ with a cavity length of $60 \mathrm{~cm}$ was measured whereas the shorter $(\sim 4 \%)$ ring-down time of 527 ns was

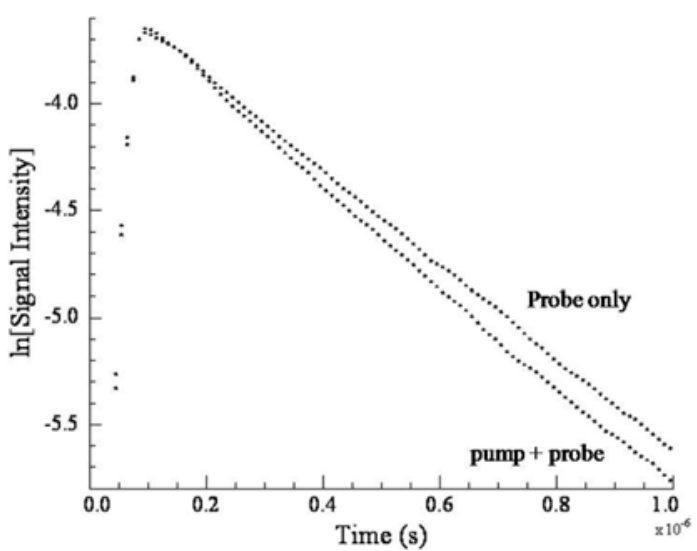

Fig. 3. The temporal probe beam intensity leaking out of the cavity with (upper) and without (lower) $\mathrm{H}_{2} \mathrm{O}_{2}$ photolysis. 
monitored due to the absorption by $\mathrm{OH}$.

\section{Results and Discussion}

The absorption coefficient $(\alpha)$ is the product of the extinction coefficient $(\sigma)$ and the concentration of the hydroxyl radical, $[\mathrm{OH}]_{t}$, at a time, $t$, after the firing of the pump or photo-dissociation beam from the excimer laser and an initial concentration of hydroxyl radical, $[\mathrm{OH}]_{0}$, decays exponentially in the pseudo-first-order reaction condition.

$$
\alpha=\sigma \cdot[O H]_{t}=\sigma \cdot[O H]_{0} \cdot e^{-k^{\prime} t}
$$

where $k^{\prime}$ is the pseudo-first order reaction rate constant.

From the above equations, a relation can be expressed as

$$
\frac{1}{t_{c}}-\frac{1}{t_{0}}=\frac{\sigma[O H]_{0} c L^{\prime}}{L} \cdot e^{-k^{\prime} t}
$$

or

$$
\ln \left(\frac{1}{t_{c}}-\frac{1}{t_{0}}\right)=\ln \left(\frac{\sigma[O H]_{0} c L^{\prime}}{L}\right)-k^{\prime} t
$$

Fig. 4 shows the plot of Eq. (6) as a function of the delay time between pump and probe beam in the presence of excess isoprene compared with $\mathrm{OH}$ which satisfies the pseudo-first order reaction condition. As the isoprene concentration increases, the slope gets steeper and the trend is similar to

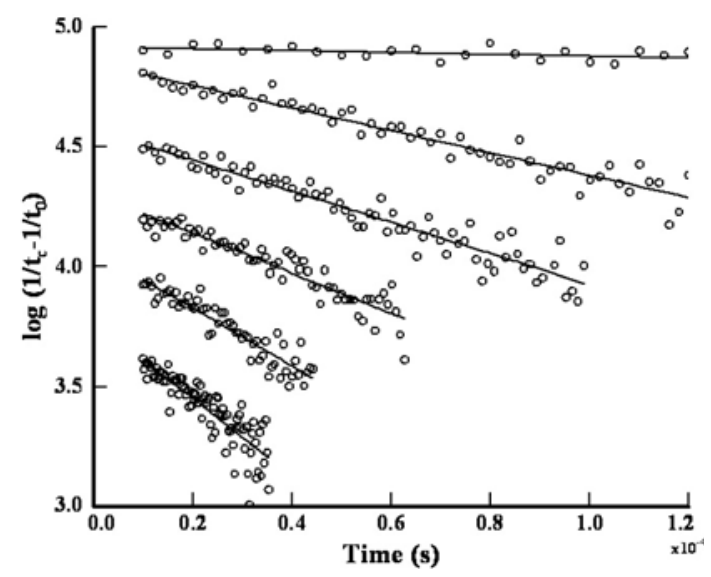

Fig. 4. Log plot of ring-down rate difference for a series of isoprene concentrations.

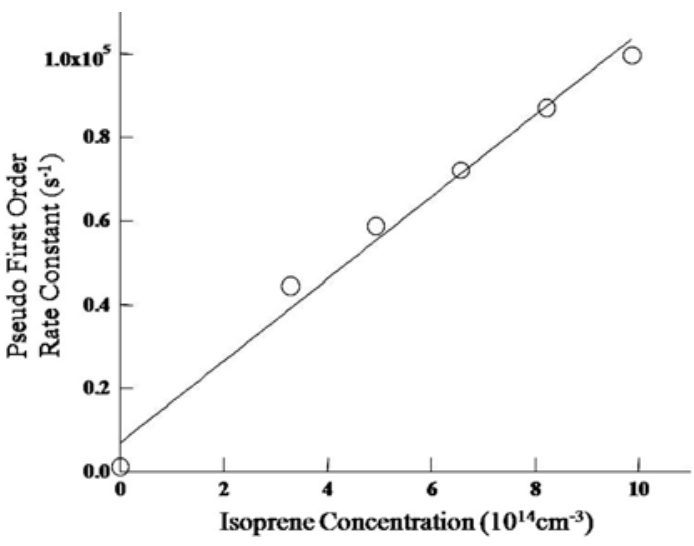

Fig. 5. Plot of pseudo-first-order reaction rate constants versus isoprene concentration for the isoprene+ $\mathrm{OH}$ reaction at 50 Torr and $295 \mathrm{~K}$.

the previous results obtained by the laser photolysis / laser-induced fluorescence (LP/LIF) method.9)

The absolute value of bimolecular reaction rate constant, $k$, was obtained from the slopes of the linear plots of $k^{\prime}$ versus isoprene concentration and it is depicted in Fig. 5. The pressure dependence of the isoprene $+\mathrm{OH}$ reaction rate has been reported by a number of groups ${ }^{9,13,14,17)}$ and it is generally accepted that the reaction is in high pressure limit regime even at 10 Torr. Hence, it is assumed that the reaction condition with the pressure of 50Torr is in high pressure limit regime. The determined rate constant of $(9.8 \pm 0.1) \times 10^{-11}$ molecule ${ }^{-1} \mathrm{~cm}^{3} \mathrm{~s}^{-1}$ is in good agreement with the previous recommendation of $1.0 \times 10^{-10}$ molecule $^{-1}$ $\mathrm{cm}^{3} \mathrm{~s}^{-1}$ by Atkinson et al. ${ }^{29)}$

As shown in Fig. 1, OH regeneration process happens in the presence of $\mathrm{NO}$ and $\mathrm{O}_{2}$, and Fig. 6 shows a $\mathrm{OH}$ cycling data using concentration of isoprene and $\mathrm{O}_{2}$ of $5.6 \times 10^{14}$ molecules $\mathrm{cm}^{-3}$ and $2.0 \times 10^{17}$ molecules $\mathrm{cm}^{-3}$, respectively. A numerical program, KINTECUS, was used to simulate the data from the experiments and the previously reported 14 reactions ${ }^{17)}$ and corresponding reaction rate constants given in Table 1 were used in the simulation. The fits of the simulation to the data are shown as solid lines in Fig. 6. The upper curve was obtained with NO concentration of $2.0 \times 10^{15}$ molecules $\mathrm{cm}^{-3}$ and exhibits the typical exponential decay at early times until the onset of recovery signal at around $50 \mu \mathrm{s} .{ }^{17,30)}$ Although there is 


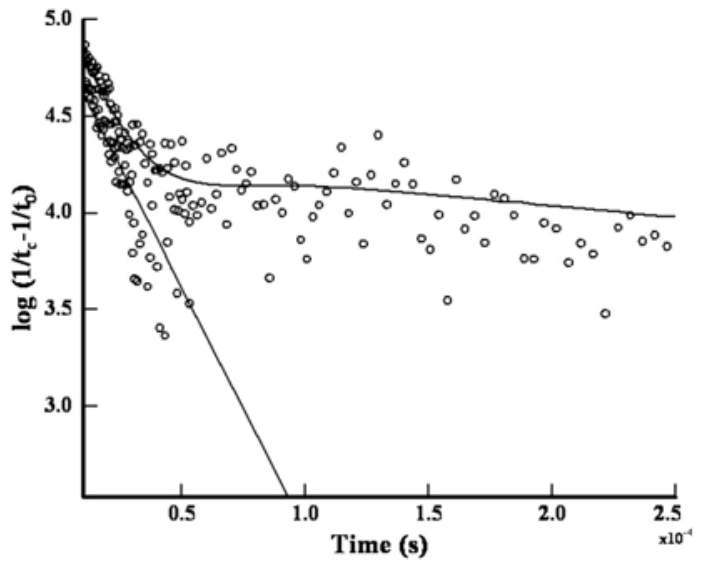

Fig. 6. Log plot of ring-down rate difference in the presence (upper line) and in the absence (lower line) of NO.

Table 1. Reaction mechanism and corresponding rate constants (molecules ${ }^{-1} \mathrm{~cm}^{3} \mathrm{~s}^{-1}$ unless the unit is noted)

\begin{tabular}{|c|c|}
\hline Reaction & Rate constant \\
\hline 1. $\mathrm{OH}+\mathrm{C}_{5} \mathrm{H}_{8} \rightarrow \mathrm{HOC}_{5} \mathrm{H}_{8}$ & 1.0 \\
\hline 2. $\mathrm{HOC}_{5} \mathrm{H}_{8}+\mathrm{O}_{2} \rightarrow \mathrm{HOC}_{5} \mathrm{H}_{8} \mathrm{O}_{2}$ & $2.3 \times 10^{-12}$ \\
\hline 3. $\mathrm{HOC}_{5} \mathrm{H}_{8}+\mathrm{NO} \rightarrow \mathrm{HOC}_{5} \mathrm{H}_{8} \mathrm{NO}$ & $1.5 \times 10^{-11}$ \\
\hline 4. $\mathrm{HOC}_{5} \mathrm{H}_{8} \mathrm{O}_{2}+\mathrm{NO} \rightarrow \mathrm{HOC}_{5} \mathrm{H}_{8} \mathrm{ONO}_{2}$ & $4.5 \times 10^{-13}$ \\
\hline 5. $\mathrm{HOC}_{5} \mathrm{H}_{8} \mathrm{O}_{2}+\mathrm{NO} \rightarrow \mathrm{HOC}_{5} \mathrm{H}_{8} \mathrm{O}+\mathrm{NO}_{2}$ & $8.6 \times 10^{-12}$ \\
\hline 6. $\mathrm{HOC}_{5} \mathrm{H}_{8} \mathrm{O} \rightarrow \mathrm{HOC}_{5} \mathrm{H}_{7} \mathrm{OH}$ & prompt $(32 \%)$ \\
\hline 7. $\mathrm{HOC}_{5} \mathrm{H}_{8} \mathrm{O} \rightarrow$ products $+\mathrm{CH}_{2} \mathrm{OH}$ & $(63 \%)$ \\
\hline 8. $\mathrm{HC}$ & $5.0 \times 10^{5} \mathrm{~s}^{-1}(5 \%$ \\
\hline 9. $\mathrm{H}$ & $3.0 \times 10^{-11}$ \\
\hline 10. $\mathrm{HOC}_{5} \mathrm{H}_{7} \mathrm{OH}+\mathrm{O}_{2} \rightarrow \mathrm{HO}_{2}+$ products & $10^{-11}$ \\
\hline 11. $\mathrm{HOC}_{5} \mathrm{H}_{7} \mathrm{OH}+\mathrm{NO} \rightarrow \mathrm{HOC}_{5} \mathrm{H}_{7} \mathrm{OHNO}$ & $3.0 \times 10^{-11}$ \\
\hline 12. $\mathrm{CH}_{2} \mathrm{OH}+\mathrm{O}_{2} \rightarrow \mathrm{HO}_{2}+\mathrm{HCHO}$ & $9.1 \times 10^{-12}$ \\
\hline 13. $\mathrm{CH}_{2} \mathrm{OH}+\mathrm{NO} \rightarrow \mathrm{CH}_{2} \mathrm{OHNO}$ & $1.2 \times 10^{-11}$ \\
\hline 14. $\mathrm{HO}_{2}+\mathrm{NO} \rightarrow \mathrm{OH}+\mathrm{NO}_{2}$ & $8.9 \times 10^{-12}$ \\
\hline
\end{tabular}

apparent signal regeneration due to the cycling of $\mathrm{OH}$, relatively large signal to noise needs to be improved to obtain a set of data showing the concentration effect of $\mathrm{O}_{2}$ and $\mathrm{NO}$ on the recovery time. In the absence of NO (lower line), the observed decay shows pseudo-first order kinetics with a rate of $1.0 \times 10^{-10}$ molecule $\mathrm{cm}^{-1} \mathrm{~s}^{-1}$, consistent with the recommendation value. ${ }^{29)}$

\section{Conclusion}

This work focuses on the verification of CRDS measurements for reaction kinetics of isoprene oxidation which results in the elevation of ozone concentration in the troposphere. The measured initial rate constant for the isoprene $+\mathrm{OH}$ reaction is in excellent agreement with previously reported value and $\mathrm{OH}$ cycling was successfully monitored. Although a direct monitoring of hydroxy peroxy radicals was not available in this study due to the lack of adequate highly reflective mirrors ranging $210 \sim 260 \mathrm{~nm}$ where the UV absorptions of typical peroxy radicals appear, ${ }^{31)}$ CRDS could be utilized to study the reaction kinetics by monitoring the ring-down time of radical species whose absorption is in the visible range in the future.

\section{Acknowledgement}

This work was supported by Korea National University Research Fund (2008). The author thank Prof. Simon North for helpful advises.

\section{References}

1. Chameides, W. L., Fehsenfeld, F., Rodgers, M. O., Cardelino, C., Martinez, J., Parrish, D., Lonneman, W., Lawson, D. R., Rasmussen, R. A., Zimmerman, P., Greenberg, J., Middleton, P., Wang, T. : Ozone precursor relationships in the ambient atmosphere. Journal of Geophyscal Research, 97, 6037-6055, 1992.

2. Rasmussen, R. A., Khalil, M. A. : Isoprene over the amazon basin. Journal of Geophyscal Research, 93, 1417-1421, 1988.

3. Atmospheric Chemistry and Global Change: Brasseur, G. P., Orlando, J. J., Tyndall, G. S., New York Oxford, Oxford University Press, 1999.

4. Fenger, J. : Urban air quality. Atmospheric Environment, 33, 4877-4900, 1999.

5. Jenkin, M. E., Hayman, G. D. : Kinetics of reactions of primary, secondary and tertiary betahydroxy peroxyl radicals-Application to isoprene degradation. Journal of the Chemical Society-Faraday Transactions, 91, 1911-1922, 1995.

6. Atkinson, R., Aschmann, S. M., Tuazon, E. C., Arey, J., Zielinska, B. : Formation of 3-methylfuran from the gas phase reaction of $\mathrm{OH}$ radicals with isoprene and the rate constant for its reaction with $\mathrm{OH}$ radical. International Journal of Chemical Kinetics, 21, 593-604, 1989.

7. Paulson, S. E., Seinfeld, J. H. : Development and evaluation of photooxidation mechanism for isoprene. Journal of Geophyscal Research, 97, 2070320715, 1992. 
8. Francisco-Marquez, M., Alvarez-Idaboy, J. R., Galano, A., Vivier-Bunge, A. : Theoretical study of the initial reaction between $\mathrm{OH}$ and isoprene in tropospheric conditions. Physical Chemistry Chemical Physics, 5, 1392-1399, 2003.

9. McGivern, W. S., Suh, I. S., Clinkenbeard, A. D., Zhang, R., North, S. W. : Experimental and computational study of the OH-isoprene reaction: Isomeric branching and low-pressure behavior. Journal of Physical Chemistry A, 104, 6609-6016, 2000.

10. Zhang, R. Y., Suh, I., Lei, W., Clinkenbeard, A. D., North, S. W. : Kinetic studies of OH-initiated reactions of isoprene. Journal of Geophyscal ResearchAtmospheres, 105, 24627-24635, 2000.

11. Stevens, P. S., Seymour, E., Li, Z. J. : Theoretical and experimental studies of the reaction of $\mathrm{OH}$ with isoprene. Journal of Physical Chemistry A, 104, 5989-5997, 2000.

12. Lei, W. F., Zhang, R. Y. : Theoretical study of hydroxyisoprene alkoxy radicals and their decomposition pathways. Journal of Physical Chemistry A, 106, 3808-3815, 2001.

13. Kleindienst, T. E., Harris, G. W., Pitts, J. N. : Rates and temperature dependences of the reaction of $\mathrm{OH}$ with isoprene, its oxidation-products, and selected terpenes. Environmental Science \& Technology, 16, 844-846, 1982.

14. Chuong, B., Stevens, P. S. : Kinetic study of the $\mathrm{OH}$ plus isoprene and $\mathrm{OH}$ plus ethylene reactions between 2 and 6 torr and over the temperature range 300-423 K. Journal of Physical Chemistry A, 104, 5230-5237, 2000.

15. Iida, Y., Obi, K., Imamura, T. : Rate constant for the reaction of $\mathrm{OH}$ radicals with isoprene at $298 \pm 2 \mathrm{~K}$. Chemistry Letters, 8, 792-793, 2002.

16. Lei, W. F., Zhang, R., McGivern, W. S., DerecskeiKovacs, A., North, S. : Theoretical study of $\mathrm{OH}-\mathrm{O}_{2-}^{-}$ isoprene peroxy radicals. Journal of Physical Chemistry A, 105, 471-477, 2001.

17. Park, J., Jongsma, G., Zhang, R., North, S. : OH/ OD Initiated oxidation of isoprene in the presence of $\mathrm{O}_{2}$ and NO. Journal of Physical Chemistry A, 108, 10688-10697, 2004.

18. Zhang, D., Zhang, R., Church, C., North, S. : Theoretical study of $\mathrm{OH}-\mathrm{O}_{2}$-isoprene peroxy radicals. Chemical Physcs Letter A, 343, 49-54, 2001.

19. Zhang, D., Suh, I., Clinkenbeard, A., Lei, W., North, S. : Kinetic studies of $\mathrm{OH}-$ initiated reactions of isoprene. Journal of Geophyscal Research-Amospheres, 105, 24627-24635, 2000.

20. O'Keefe, A., Deacon, D. A. : Cavity ring-down optical spectrometer for absorption measurements using pused laser sources. Review of Scientific
Instruments, 59, 2544-2551, 1988.

21. Pushkarsky, M. B., Zalyubovsky, S. J., Miller, T. A. : Detection and characterization of alkyl peroxy radicals using cavity ringdown spectroscopy. Journal of Chemical Physics, 112, 10695-10698, 2000.

22. Rupper, P., Sharp, E. N., Tarczay, G., Miller, T. A. : Investigation of ethyl peroxy radical conformers via cavity ringdown spectroscopy of the $\tilde{A}-\tilde{B}$ electronic transition. Journal of Physical Chemistry A, 111, 832-840, 2007.

23. Liu, Y. D., Morales-Cueto, R., Hargrove, J., Medina, D., Zhang, J. S. : Measurements of peroxy radicals using chemical amplification-cavity ringdown spectroscopy. Environmental Science \& Technology, 43, 7791-7796, 2009.

24. Choi, Y. M., Xia, W. S., Park, J., Lin, M. C. : Kinetics and mechanism for the reaction of phenyl radical with formaldehyde. Journal of Physical Chemistry A, 104, 7030-7035, 2000.

25. Park, J., Tokmakov, I. V., Lin, M. C. : Experimental and computational studies of the phenyl radical reaction with Allene. Journal of Physical Chemistry A, 111, 6881-6889, 2007.

26. Atkinson, D. B., Hudgens, J. W. : Chemical kinetic studies using ultraviolet cavity ring-down spectroscopic detection: Self-reaction of ethyl and ethylperoxy radicals and the reaction $\mathrm{O}_{2}+\mathrm{C}_{2} \mathrm{H}_{5^{-}}$ $>\mathrm{C}_{2} \mathrm{H}_{5} \mathrm{O}_{2}$. Journal of Physical Chemistry A, 101, 3901-3909, 1997.

27. Atkinson, D. B., Hudgens, J. W., Orr-Ewing, A. J. : Kinetic studies of the reactions of IO radicals determined by cavity ring-down spectroscopy. Journal of Physical Chemistry A, 103, 6173-6180, 1999.

28. Atkinson, D. B., Hudgens, J. W. : Chlorination chemistry. 2. Rate coefficients, reaction mechanism, and spectrum of the chlorine adduct of allene. Journal of Physical Chemistry A, 104, 811-818, 2000.

29. Summary of Evaluated Kinetic and Phtochemical Data for Atmospheric Chemistry. IUPAC Subcommittee on Gas Kinetic Data Evaluation for Atmospheric Chemistry : Atkinson, R., Baulch, D. L., Cox, R. A., Crowley, J. N., Hampson, R. F. Jr., Kerr, J. A., Rossi, M. J., Troe, J., London, Blackwell, 2002.

30. Chen, X. H., Hulbert, D., Shepson, P. B. : Measurement of the organic nitrate yield from $\mathrm{OH}$ reaction with isoprene. Journal of Geophyscal Research-Atmospheres, 109, 25563-25568, 1998.

31. Wallington, T. J., Dagaut, P., Kurylo, M. J. : Ultraviolet absorption cross sections and reaction kinetics and mechanisms for peroxy radicals in the gas phase. Chemical Review, 92, 667-710, 1992. 